\title{
A Modified Calculation Improves the Accuracy of Predicted Postoperative Lung Function Values in Lung Cancer Patients
}

\author{
G. Schlachtenberger ${ }^{1}$ (I) F. Doerr ${ }^{1} \cdot$ H. Menghesha ${ }^{1} \cdot$ L. Hagmeyer $^{2} \cdot$ T. Leschczyk $^{3} \cdot$ C. Gaisendrees $^{1} \cdot$ M. Michel $^{4}$. \\ T. Wahlers ${ }^{1} \cdot$ K. Hekmat ${ }^{1}$ - M. B. Heldwein ${ }^{1}$
}

Received: 24 May 2021 / Accepted: 1 August 2021 / Published online: 13 August 2021

(c) The Author(s) 2021

\begin{abstract}
Purpose Preoperative pulmonary function testing is mandatory for non-small cell lung cancer (NSCLC) surgery. The predicted postoperative FEV1 (ppoFEV1) is used for further risk stratification. We compared the ppoFEV1 with the postoperative FEV1 (postFEV1) in order to improve the calculation of the ppoFEV1.

Methods 87 patients voluntarily received an FEV1 assessment 1 year after surgery. ppoFEV1 was calculated according to the Brunelli calculation. Baseline characteristics and surgical procedure were compared in a uni- and multivariate analysis between different accuracy levels of the ppoFEV1. Parameters which remained significant in the multinominal regression analysis were evaluated for a modification of the ppoFEV1 calculation.

Results Independent factors for a more inaccurate ppoFEV1 were preoperative active smoking (odds ratio (OR) 4.1, confidence interval (CI) 3.6-6.41; $p=0.01$ ), packyears (OR 4.1, CI 3.6-6.41; $p=0.008$ ), younger age (OR 1.1, CI 1.01-1.12; $p=0.03$ ), and patients undergoing pneumectomy (OR 5.55, CI 1.35-23.6; $p=0.01$ ). For the customized ppoFEV1 we excluded pneumonectomies. For patients $<60$ years, an additional lung segment was added to the calculation. ppoFEV $1=$ preFEV $1 \times 1-\left(\frac{\text { Lung segments resected }+1}{\text { Total number of segments }}\right)$. For actively smoking patients with more than 30 packyears we subtracted one lung segment from the calculation ppoFEV1 $=$ PreFEV1 $\times 1-\left(\frac{\text { Lung segments resected }-1}{\text { Total number of segments }}\right)$.

Conclusion We were able to enhance the predictability of the ppoFEV1 with modifications. The modified ppoFEV1 $(1.8281 \pm 0.4791)$ closely approximates the postFEV1 of $1.8231 \pm 0.4761,(0.27 \%)$ while the original ppoFEV 1 calculation is at $1.781 \pm 0.53(2.19 \%)$. However, if patients require pneumectomy, more complex techniques to determine the ppoFEV1 should be included to stratify risk.
\end{abstract}

Keywords Customizing the ppoFEV1 1 ppoFEV1 $\cdot$ Non-small cell lung cancer $\cdot$ Lung function $\cdot$ Risk stratification

G. Schlachtenberger

Georg.Schlachtenberger@uk-koeln.de

1 Department of Cardiothoracic Surgery, University Hospital of Cologne, Kerpenerstrasse 62, 50937 Cologne, Germany

2 Clinic for Pneumology and Allergology, Hospital Bethanien, Aufderhöher Strasse. 169-175, 42699 Solingen, Germany

3 School of Medicine, University of Cologne, Cologne, Germany

4 Faculty of Mathematics and Natural Sciences, Institute of Zoology, University of Cologne, Zuelpicher Strasse 47b, 62, 50674 Cologne, Germany

\section{Introduction}

Anatomical lung resection is the gold standard for the treatment of early-stage non-small cell lung cancer (NSCLC) [1]. Pulmonary function testing is a cornerstone of the preoperative physiological assessment of patients that is being evaluated for surgical resection. Pulmonary function is often impaired in patients with resectable tumors because of frequent pulmonary comorbidities. Therefore, a precise preoperative assessment, including the measurement of the forced expiratory volume in $1 \mathrm{~s}$ (FEV1) and the diffusing capacity of the lung for carbon monoxide (DLCO) is important $[2,3]$. The lower threshold values whether patients are suitable for lobectomy or pneumectomy are clearly defined in the guidelines [2-5]. Morbidity rates are substantially 
increased when lobectomies are performed in patients with FEV $1<1.51$, DLCO $<50 \%$ or pneumectomies with FEV $1>21$, DLCO $<60 \%$ [2, 6-8]. The predicted postoperative FEV1 (ppoFEV1) plays a significant role in assessing postoperative lung function $[2,6,9,10]$. There are various methods available for evaluating the ppoFEV1 such as quantitative CT scans [11], where tumor volume (including the segment or lobe to be resected) is subtracted from total lung volume. Despite those methods there is the long established and simple to use ppoFEV1 calculation method [2,9]. This approach, which calculates the removed segments in ratio to the remaining, was implemented by Brunelli et al. [2,9]. The advantage of this method is that pulmonary risk stratification is feasible during multidisciplinary team (MDT) conferences. The method however remains controversial due to its simplicity. Therefore, many different methods were established for a more accurate prediction of the postoperativeFEV1 (postFEV1) [11, 12]. The ppoFEV1 is routinely implemented in our department during MDT. Therefore, we decided to compare and contrast the ppoFEV1 with the postFEV1 one year after surgery. We primarily aimed to estimate the accuracy of the ppoFEV1 for particular baseline characteristics and surgical procedures. Additionally, we wanted to see whether we could identify subpopulations of patients in order to modify ppoFEV1 calculation to improve accuracy compared to the actual postFEV1.

\section{Material and Methods}

All relevant patient data were taken from the electronic hospital information system of our institute. 87 patients voluntarily presented to our out-patient department 1 year after surgery for a routine surgical check-up which included a pulmonary function test. We included all patients who received a postFEV1 in our analysis.

\section{Calculation of the ppoFEV1}

The ppoFEV1 is calculated based on the preoperative FEV1 (preFEV1), the number of functional lung segments resected (y), and the total number of functional segments available at time of resection $(\mathrm{z})$. PpoFEV $1=\operatorname{preFEV} 1 \times 1-\left(\frac{y}{z}\right)[2,9$, 12]. Unless patients have to undergo a redo operation, the total number of segments for both lungs is 19: 10 in the right lung ( 3 upper, 2 middle, 5 lower lobe) and 9 in the left lung (5 upper and 4 lower lobe).

\section{Statistical Analysis}

After calculating the ppoFEV1, we compared our results with the postFEV1 1 year after surgery.
We determined accuracy levels and classified the deviation of the ppoFEV1 in relation to the postFEV1. In order to reflect the greatest differences, we defined the accuracy level of $\pm 2 \%$ as most accurate, the accuracy level of $\pm 10 \%$ as moderately accurate, and the accuracy level of $\pm>10 \%$ as inaccurate. We performed a subgroup analysis excluding the ppoFEV $1 \pm 2 \%$ from the ppoFEV $1 \pm 10 \%$, in order to prevent counting ppoFEV $1 \pm 2 \%$ patients twice. These patients were defined as ppoFEV $1 \pm 10 \%> \pm 2 \%$. We analyzed baseline characteristics and surgical procedures which eventually resulted in the most accurate- or inaccurate ppoFEV 1 with univariate and multivariate analyses.

In cases where univariate analysis showed significant differences, we performed a multinominal regression analysis for further evaluation. Multinomial differences are described by odds ratio (OR) and $95 \%$ confidence interval (CI). Categorical variables were analyzed using Pearson's $\chi^{2}$ or Fisher's exact test. Continuous parameters were expressed as mean \pm standard deviation (SD) and were analyzed by an unpaired Student $t$ test. $p$-value $<0.05$ was considered statistically significant. Statistical analysis was performed using the SPSS statistical software package (Version 25; IBM, Armonk, NY, USA).

\section{Customization of the ppoFEV1}

Significant multinominal parameters were included in our customizing process. The primary objective of this customization was to determine baseline characteristics or surgical procedures which could be included in the calculation in order to improve the ppoFEV1.

The customizing process is explained in the results part. The formulas calculated by us are the following.

For patients $<60$ years, an additional lung segment is a d d d to the calculation ppoFEV $1=$ preFEV $1 \times 1-\left(\frac{\text { Lung segments resected }+1}{\text { Total number of segments }}\right)$. For actively smoking patients with more than 30 packyears one lung segment is subtracted from the calculation ppoFEV $1=$ PreFEV $1 \times 1-\left(\frac{\text { Lung segments resected }-1}{\text { Total number of segments }}\right)$.

\section{Results}

A total of 464 patients underwent anatomical pulmonary resections since 2012 at our institution. 87 (18.8\%) patients presented voluntarily for a postoperative checkup and a redo assessment of their pulmonary function 1 year after surgery. We classified patients into categories according to how accurately the ppoFEV 1 predicted the postFEV1. The ppoFEV 1 of $79 \%$ patients showed moderate accuracy of $\pm 10 \%$. $24 \%$ of patients were most accurately predicted with $\pm 2 \%$ deviation. Calculated values 
exceeded $> \pm 10 \%$ in $21 \%$ of patients. 51 (45\%) patients showed a ppoFEV $1 \pm 10 \%> \pm 2 \%$ accuracy level. The mean preFEV1 of the cohort was 2.341 (1) \pm 0.611 and the mean postFEV1 was $1.821 \pm 0.471$, respectively. Calculation of the ppoFEV1 yielded $1.781 \pm 0.531$ (2.19\%).

\section{Baseline Characteristics-Univariate Analysis}

The baseline characteristics according to the predictive accuracy level are presented in Tables 1 and 2. We compared patients with the most accurate ppoFEV $1 \pm 2 \%$ with patients with moderate

Table 1 Baseline characteristics ppoFEV $1 \pm 10 \%> \pm 2 \%$ vs. ppoFEV $1 \pm 2 \%$

\begin{tabular}{|c|c|c|c|c|c|}
\hline & $\begin{array}{l}\text { Total cohort } \\
n=87\end{array}$ & $\begin{array}{l}\text { ppoFEV } 1 \pm 10 \% \pm 2 \% \\
n=51(45 \%)\end{array}$ & $\begin{array}{l}\text { ppoFEV } 1 \pm 2 \% \\
n=21(24 \%)\end{array}$ & $\begin{array}{l}\text { Univariate } \\
p \text {-value }\end{array}$ & $\begin{array}{l}\text { Multivariate } \\
p \text {-value }\end{array}$ \\
\hline Age (years) & $63.9 \pm 7.7$ & $64.9 \pm 6.7$ & $65.1 \pm 5.9$ & 0.99 & \\
\hline Female gender $n .(\%)$ & $40(46)$ & $22(48.3)$ & $8(38.1)$ & 0.26 & \\
\hline Preoperative FEV1 (1/s) & $2.34 \pm 0.61$ & $2.27 \pm 0.60$ & $2.33 \pm 0.52$ & 0.67 & \\
\hline Preoperative FEV1 in \% & $84.4 \pm 18.2$ & $82.1 \pm 15.4$ & $85.8 \pm 17.3$ & 0.46 & \\
\hline Postoperative FEV1 (1/s) & $1.82 \pm 0.47$ & $1.73 \pm 0.45$ & $1.84 \pm 0.44$ & 0.38 & \\
\hline Preoperative DLCO in \% & $81.0 \pm 19.0$ & $77.3 \pm 19.9$ & $87.4 \pm 17.7$ & 0.05 & 0.06 \\
\hline Postoperative DLCO in $\%$ & $78.3 \pm 19.8$ & $75.0 \pm 18.7$ & $82.5 \pm 22.3$ & 0.19 & \\
\hline $\operatorname{BMI}\left(\mathrm{kg} / \mathrm{m}^{2}\right)$ & $25.3 \pm 4.2$ & $25.5 \pm 4.4$ & $26.1 \pm 4.4$ & 0.65 & \\
\hline \multicolumn{6}{|l|}{ Smoking } \\
\hline Active smoking $n .(\%)$ & $65(74.7)$ & $35(77.8)$ & $15(68.4)$ & 0.33 & \\
\hline Smoking in packyears & $43.8 \pm 24.9$ & $44.9 \pm 27.9$ & $33.4 \pm 14.1$ & $\mathbf{0 . 0 3}$ & 0.08 \\
\hline Heavy smoker $>30$ py $n .(\%)$ & $62(74.7)$ & $31(68.9)$ & $15(71.4)$ & 0.9 & \\
\hline COPD $n .(\%)$ & $31(35.6)$ & $13(40.0)$ & $6(28.6)$ & 0.29 & \\
\hline CVD n. (\%) & $21(24.1)$ & $18(26.9)$ & $5(23.8)$ & 0.47 & \\
\hline
\end{tabular}

Significant values are highlighted in bold

$B M I$ body mass index, COPD chronic obstructive pulmonary disease, $C V D$ cardiovascular disease, FEV1 forced expiratory volume in $1 \mathrm{~s}$, ppoFEV1 predicted postoperative FEV1, DLCO diffusing capacity for carbon monoxide, $P Y$ packyears

Table 2 Baseline characteristics ppoFEV1 $\pm 10 \%$ vs. ppoFEV1 $> \pm 10 \%$

\begin{tabular}{|c|c|c|c|c|c|}
\hline & $\begin{array}{l}\text { Total cohort } \\
n=87\end{array}$ & $\begin{array}{l}\text { ppoFEV } 1 \pm 10 \% \\
n=69(79 \%)\end{array}$ & $\begin{array}{l}\text { ppoFEV1> } 10 \% \\
n=18(21 \%)\end{array}$ & $\begin{array}{l}\text { Univariate } \\
p \text {-value }\end{array}$ & $\begin{array}{l}\text { Multivariate } \\
p \text {-value }\end{array}$ \\
\hline Age (years) & $63.9 \pm 7.7$ & $65.1 \pm 6.5$ & $59.7 \pm 10.3$ & 0.01 & 0.04 \\
\hline Female gender $n .(\%)$ & $40(46)$ & $32(46.4)$ & $8(44.4)$ & 0.99 & \\
\hline Preoperative FEV1 (1/s) & $2.34 \pm 0.61$ & $2.39 \pm 0.57$ & $2.60 \pm 0.76$ & 0.05 & 0.5 \\
\hline Preoperative FEV1 in \% & $84.4 \pm 18.2$ & $83.8 \pm 16.0$ & $86.4 \pm 26.0$ & 0.48 & \\
\hline Postoperative FEV1 (1/s) & $1.82 \pm 0.47$ & $1.83 \pm 0.45$ & $1.99 \pm 0.55$ & 0.1 & \\
\hline Preoperative DLCO in $\%$ & $81.0 \pm 19.0$ & $80.8 \pm 19.7$ & $82.1 \pm 17.1$ & 0.94 & \\
\hline Postoperative DLCO in \% & $78.3 \pm 19.8$ & $78.1 \pm 20.3$ & $79.1 \pm 18.2$ & 0.65 & \\
\hline BMI $\left(\mathrm{kg} / \mathrm{m}^{2}\right)$ & $25.3 \pm 4.2$ & $25.7 \pm 4.4$ & $24.8 \pm 2.9$ & 0.34 & \\
\hline \multicolumn{6}{|l|}{ Smoking } \\
\hline Active smoking $n .(\%)$ & 74.7 & $49(71.0)$ & $18(100)$ & 0.005 & 0.01 \\
\hline Smoking in packyears & $43.8 \pm 24.9$ & $41.2 \pm 24.5$ & $61.4 \pm 19.1$ & 0.002 & 0.008 \\
\hline Heavy smoker $>30$ py $n .(\%)$ & $62(71.3)$ & $51(73.9)$ & $18(100)$ & 0.001 & 0.004 \\
\hline COPD $n .(\%)$ & 35.6 & $25(36.2)$ & $6(33.3)$ & 0.52 & \\
\hline CVD n. (\%) & 24.1 & $18(26.1)$ & 3 (16.7) & 0.38 & \\
\hline
\end{tabular}

Significant values are highlighted in bold

$B M I$ body mass index, COPD chronic obstructive pulmonary disease, $C V D$ cardiovascular disease, FEV1 forced expiratory volume in $1 \mathrm{~s}$, ppoFEV1 predicted postoperative FEV1, DLCO diffusing capacity for carbon monoxide, $P Y$ packyears 
deviation ppoFEV $1 \pm 10 \%> \pm 2 \%$. Secondly, we compared the poorest group of ppoFEV $1> \pm 10 \%$ with the ppoFEV $1 \pm 10 \%$ group. Age did not differ between ppoFEV $1 \pm 2 \%$ and ppoFEV $1 \pm 10 \%> \pm 2 \%$. Patients with ppoFEV $1> \pm 10 \%$ on the other hand were significantly younger than ppoFEV $1 \pm 10 \%$ patients $(59.7 \pm 10.3$ years vs $65.1 \pm 6.5$ years, $p=0.01$ ).

The distribution of age in relation of the ppoFEV1 is shown in Fig. 1. The preFEV1 differed significantly between ppoFEV $1> \pm 10 \%$ and ppoFEV $1 \pm 10 \%$ (2.61 $1 \pm 0.741$ vs. $2.391 \pm 0.571, p=0.05)$. The preoperative DLCO \% (preDLCO \%) of patients with ppoFEV1 $\pm 2 \%$ showed a significantly higher value $(87.4 \pm 17.7)$ than in ppoFEV $1 \pm 10> \pm 2 \%$ patients $(77.3 \pm 19.9)(p=0.05)$. The postDLCO however did not differ between $\pm 2 \%$ and $\pm 10> \pm 2 \% .74 .7 \%$ of patients were active smokers at the time of surgery (active smoking: smoking in 3 months prior to surgery). Active smoking did not differ between ppoFEV $1 \pm 2 \%$ and ppoFEV $1 \pm 10 \%> \pm 2 \% .100 \%$ of ppoFEV $1> \pm 10 \%$ patients were active smokers compared to $71.0 \%$ of ppoFEV $1 \pm 10 \%$ ( $p=0.005$, Table 2$)$. Preoperative smoking was counted in packyears. The influence of smoking on the postFEV1 is presented in Fig. 1. Patients with ppoFEV $1 \pm 2 \%$ smoked significantly fewer packyears compared to patients with $\pm 10 \%> \pm 2 \%$ (33.4 \pm 14.1 vs. $44.9 \pm 27.9, p=0.03)$. Patients with ppoFEV $1> \pm 10 \%$ smoked significantly more than ppoFEV $1 \pm 10 \%$ patients $(61.4 \pm 19.1$ vs. $41.2 \pm 24.5 p=0.002)$. Heavy smoking is defined as $>30$ packyears [2,9]. Heavy smoking did not differ between patients with ppoFEV $1 \pm 2 \%$ and ppoFEV $1 \pm 10 \%> \pm 2 \%$. PpoFEV $1> \pm 10 \%$ patients were significantly more often heavy smokers than ppoFEV $1 \pm 10 \%$ patients $(100 \%$ vs. $73.1, p=0.001)$.

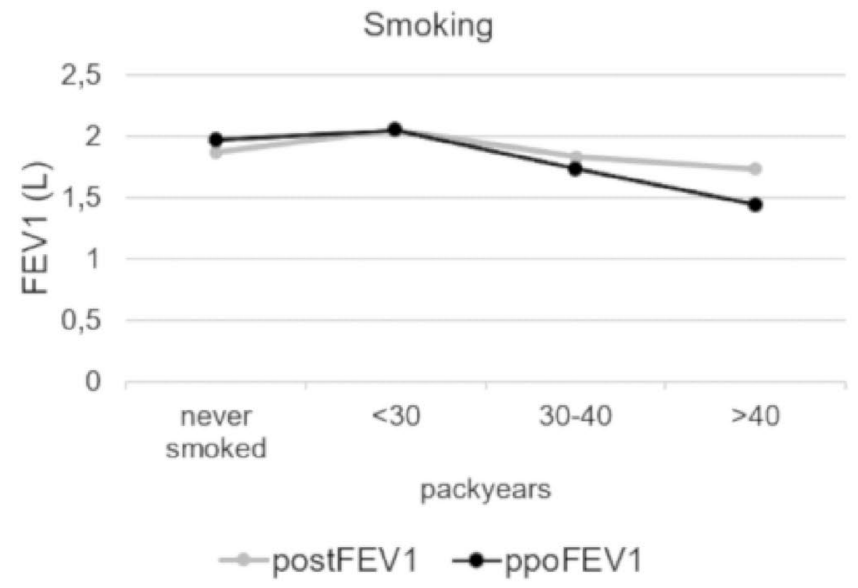

Fig. 1 Diagrams showing the comparison of the postoperative FEV1 in liters (gray lines) to the ppoFEV1 in liters (black lines). Comparison of smoking in packyears, Comparison of age in years. FEVI

\section{Baseline Characteristics-Multivariate Analysis}

We carried out a multinominal regression analysis for further evaluation of significant results from the univariate analysis (included in Tables 1,2). In the comparison between the accurate predictive group (ppoFEV1 $\pm 2 \%$ ) with moderate ppoFEV $1 \pm 10 \%> \pm 2 \%$, we found that neither preDLCO nor the number of packyears were independent factors for a more accurate ppoFEV1 in the multivariate analysis (OR 0.97, CI 0.94-1.02; $p=0.07$; OR 2.3, CI $0.92-6.12 ; p=0.07$, respectively). However, younger age (OR 1.1, CI 1.01-1.12; $p=0.03$ ), active smoking (OR 1.21, CI $0.95-1.62 ; p=0.01$ ), packyears (OR 4.1, CI 3.6-6.41; $p=0.008$ ), and heavy smoking ( $>30$ packyears) (OR 2.15, CI $0.89-3.12 ; p=0.004)$ were independent factors for a more inaccurate ppoFEV1.

\section{Perioperative Characteristics-Univariate Analysis}

The perioperative characteristics subdivided into different accuracy levels are presented in Tables 3 and 4. Patients with a ppoFEV $1 \pm 2 \%$ underwent a right upper lobe resection significantly more often compared to the ppoFEV $1 \pm 10 \%> \pm 2 \%$ ( $42.9 \%$ vs. $20.0 \%, p=0.05$ ). The right lower lobe was resected less often in patients with ppoFEV $1 \pm 2 \%$ (29.9\% vs. 9.5\%, $p=0.04)$. Patients with ppoFEV $1 \pm 2 \%$ never underwent pneumectomy ( 0 vs. $3.0 \%$ ) or bilobectomy ( $0 \%$ vs. $6.0 \%$ ). The most inaccurate FEV $1> \pm 10 \%$ was significantly more frequent in patients undergoing pneumectomy ( $17.0 \%$ vs. $2.9 \%, p=0.003)$ (Fig. 2).

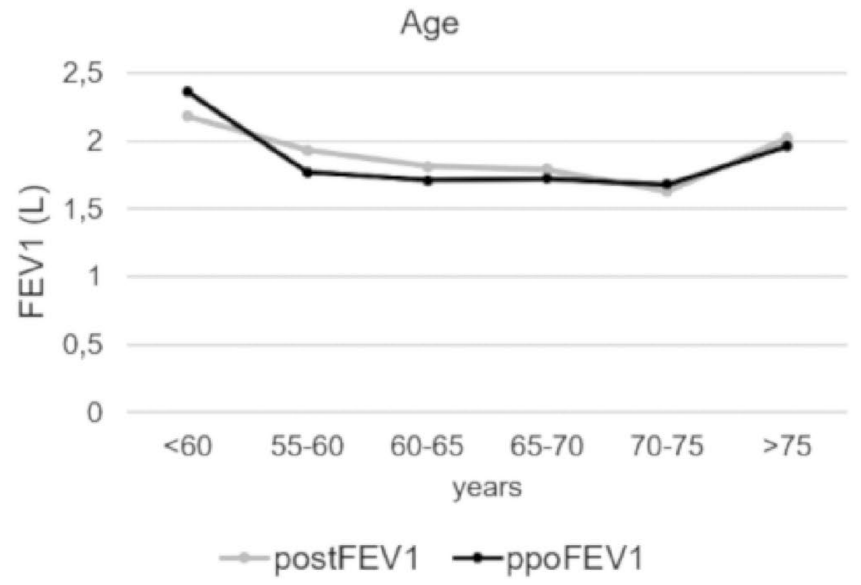

forced expiratory volume in $1 \mathrm{~s}$, postFEV1 postoperative FEV1, ppoFEV1 predicted postoperative FEV1 
Table 3 Perioperative characteristics ppoFEV $1 \pm 10 \%> \pm 2 \%$ vs. ppoFEV $1 \pm 2 \%$

\begin{tabular}{|c|c|c|c|c|c|}
\hline & $\begin{array}{l}\text { Total cohort } \\
n=87\end{array}$ & $\begin{array}{l}\text { ppoFEV } 1 \pm 10 \%> \pm 2 \% \\
n=51(45 \%)\end{array}$ & $\begin{array}{l}\text { ppoFEV } 1 \pm 2 \% \\
n=21(24 \%)\end{array}$ & $\begin{array}{l}\text { Univariate } \\
p \text {-value }\end{array}$ & $\begin{array}{l}\text { Multivariate } \\
p \text {-value }\end{array}$ \\
\hline Left UL-resection $n .(\%)$ & $21(24.1)$ & $8(17.8)$ & $8(38.1)$ & 0.06 & \\
\hline Left LL-resection $n .(\%)$ & $12(13.8)$ & $7(15.6)$ & $2(9.5)$ & 0.7 & \\
\hline Right UL-resection n. (\%) & $21(24.1)$ & $9(20.0)$ & $9(42.9)$ & 0.05 & 0.17 \\
\hline ML-resection $n .(\%)$ & $6(6.9)$ & $4(8.9)$ & 0 & 0 & \\
\hline Right LL-resection $n .(\%)$ & $18(20.7)$ & $12(26.9)$ & $2(9.5)$ & 0.04 & 0.13 \\
\hline Bi-lobectomy $n .(\%)$ & $4(4.6)$ & $3(6.7)$ & 0 & 0 & \\
\hline Pneumectomy $n .(\%)$ & $5(5.7)$ & $2(4.4)$ & 0 & 0 & \\
\hline Tumor size in $\mathrm{cm}$ & $2.4 \pm 1.7$ & $2.4 \pm 1.7$ & $2.4 \pm 1.6$ & 0.9 & \\
\hline Adjuvant therapy $n .(\%)$ & $17(21.8)$ & $8(17.8)$ & $5(23.8)$ & 0.25 & \\
\hline
\end{tabular}

Significant values are highlighted in bold

ppoFEV1 predicted postoperative forced expiratory volume in $1 \mathrm{~s}, M L$ middle lobe, $L L$ lower lobe, $U L$ upper lobe

Table 4 Perioperative ppoFEV $1 \pm 10 \%$ vs. ppoFEV $1> \pm 10 \%$

\begin{tabular}{|c|c|c|c|c|c|}
\hline & $\begin{array}{l}\text { Total cohort } \\
n=87\end{array}$ & $\begin{array}{l}\text { ppoFEV } 1 \pm 10 \% \\
n=69(77 \%)\end{array}$ & $\begin{array}{l}\text { ppoFEV } 1> \pm 10 \% \\
n=18(21 \%)\end{array}$ & $\begin{array}{l}\text { Univariate } \\
p \text {-value }\end{array}$ & $\begin{array}{l}\text { Multivariate } \\
p \text {-value }\end{array}$ \\
\hline Left UL-resection $n .(\%)$ & $21(24.1)$ & $16(23.2)$ & $5(27.8)$ & 0.76 & \\
\hline Left LL-resection $n .(\%)$ & $12(13.8)$ & $10(14.5)$ & $3(16.7)$ & 0.9 & \\
\hline Right UL-resection $n .(\%)$ & $21(24.1)$ & $18(26.1)$ & $3(16.7)$ & 0.27 & \\
\hline ML-resection $n .(\%)$ & $5(5.7)$ & $5(8.7)$ & 0 & 0 & \\
\hline Right LL-resection $n .(\%)$ & $19(21.8)$ & $13(19.0)$ & $5(27.8)$ & 0.29 & \\
\hline Bi-lobectomy $n .(\%)$ & $4(4.6)$ & $4(5.8)$ & 0 & 0 & \\
\hline Pneumectomy $n .(\%)$ & $5(5.7)$ & $1(1.4)$ & $4(22.2)$ & 0.004 & 0.02 \\
\hline Tumor size in $\mathrm{cm}$ & $2.4 \pm 1.7$ & $2.7 \pm 1.8$ & $2.1 \pm 1.2$ & 0.9 & \\
\hline Adjuvant therapy $n .(\%)$ & $17(21.8)$ & $13(19.4)$ & $3(18.7)$ & 0.35 & \\
\hline
\end{tabular}

Significant values are highlighted in bold

ppoFEVI predicted postoperative forced expiratory volume in $1 \mathrm{~s}, M L$ middle lobe, $L L$ lower lobe, $U L$ upper lobe

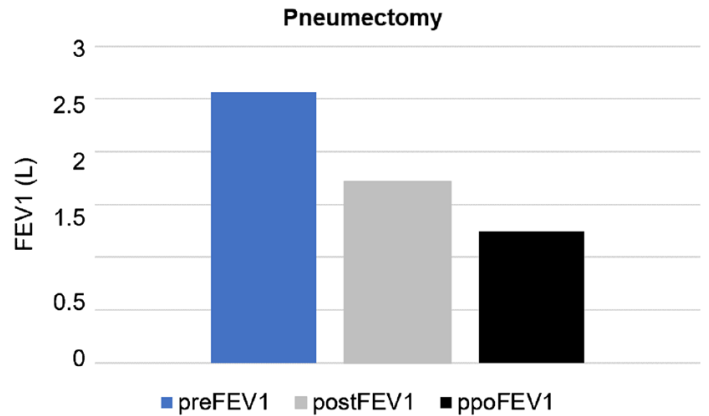

Fig. 2 Bar chart showing the comparison of pneumonectomies $(n=5)$ regarding the mean preoperative FEV1 (blue bar), postoperative FEV1 (gray bar), and ppoFEV1 (black bar). FEV1 forced expiratory volume in $1 \mathrm{~s}$, preFEV1 preoperative FEV1, postFEV1 postoperative FEV1, ppoFEV1 predicted postoperative FEV1

\section{Perioperative Characteristics-Multivariate Analysis}

The multinominal regression of the relevant baseline characteristics is presented in Tables 3 and 4. Both upper and lower lobe resections were no independent factors in the multivariate analysis (OR 0.44, CI $0.12-1.41 ; p=0.14$ ) (OR 2.28, CI $0.61-6.77 ; p=0.16)$. Pneumectomy on the other was an independent factor for ppoFEV1> $>15 \%$ in the multivariate analysis (OR 5.65, CI 1.46-23.6; $p=0.02$ ) (Fig. 2).

\section{Customizing the ppoFEV1}

According to the results of the multinominal regression analysis, we picked parameters with the greatest impact on the accuracy of the ppoFEV1. Patient age, active smoking status, packyears, and pneumectomy where the parameters with the strongest influence on the accuracy levels of the ppoFEV1. We demonstrated that the calculation of ppoFEV1 was 
more likely to yield falsely high values in younger patients (Table 2, Fig. 1). We illustrated that active heavy smokers showed lower ppoFEV1 values (Table 2, Fig. 1). Finally, we showed that pneumectomy was an independent factor for an inaccurate measurement of the ppoFEV1 (Table 4, Fig. 2).

To improve the accuracy of the ppoFEV1, we tried to keep the method as simple as possible.

1. We excluded Pneumectomies.

2. We added an additional lung segment to the calculation in patients younger than 60 years.

3. We subtracted one lung segment from the calculation for patients who were active smokers with more than 30 packyears at the time of surgery.

4. When patients were both $(2)<60$ years and (3) active heavy smokers we used the original calculation as the modifications canceled each other.

In the following section we give two computational examples with the preFEV1 of two patients explaining our customized ppoFEV1.

Patient undergoing an upper right lobe resection $<60$ years:

ppoFEV $1=$ preFEV1 $11-\left(\frac{\text { Number of lung segments resected }+1}{\text { Total number of segments }}\right)$ preFEV $1=2.67 \mathrm{l}$; postFEV $1=2.04 \mathrm{l}$; ppoFEV 12.251 Calculation method: $2.671 \times 1-\left(\frac{3}{19}\right)=$ ppoFEV $1=2.251$.

Customized method: $2.671 \times 1-\left(\frac{3+1}{19}\right)=$ ppoFEV1 $=2.111$. Accuracy deviation $6.86 \%$.

Patient undergoing a lower left lobe resection heavy smoker:

p p o F E V 1 = P r e F E V 1 × $1-\left(\frac{\text { Number of lung segments resected }-1}{\text { Total number of segments }}\right)$. A c t u a 1 preFEV $1=1.77$ 1; postFEV $1=1.48$ 1; ppoFEV 11.401 . Calculation method: $1.77 \times\left(1-\frac{4}{19}\right)=$ ppoFEV $1=1.401$.

Customized method: $1.77 \times\left(1-\frac{4-1}{19}\right)=$ ppoFEV1 $=1.491$. Accuracy deviation $4.73 \%$.

The mean postFEV1 was $1.8231 \pm 0.4761$. By customizing the ppoFEV1 the calculation was more accurate $(1.8281 \pm 0.4791)(0.27 \%)$ compared to the original ppoFEV1 (1.78 1 \pm 0.531$)(2.19 \%)$. In addition, customization also led to a redistribution of the accuracy levels we classified (Fig. 3).

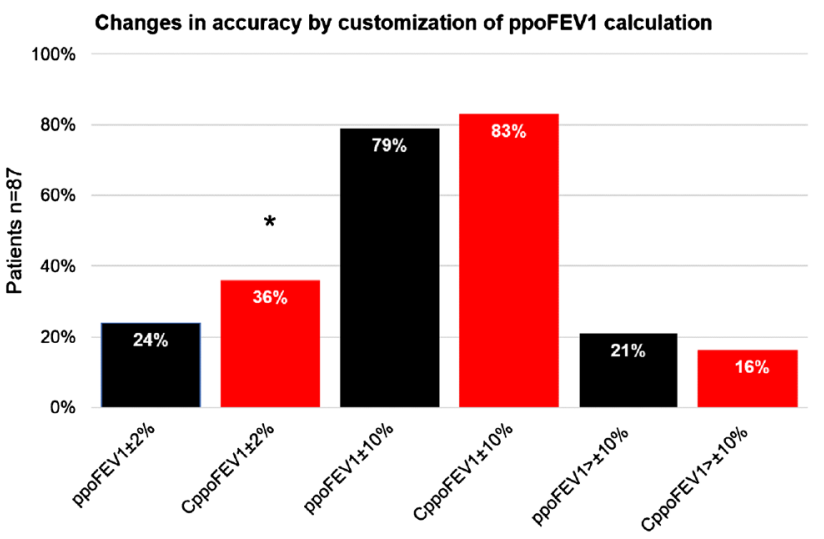

Fig. 3 Bar charts showing the comparison of the modified ppoFEV1 (red bars) and the original ppoFEV1 (black bars) subdivided into the accuracy levels ppoFEV $1 \pm 2 \%, 10 \%$, and $>10 \%$. Asterisk showing significant values $(p=0.01)$ between original ppoFEV $1 \pm 2 \%$ and customized ppoFEV1. FEV1 forced expiratory volume in $1 \mathrm{~s}$, ppoFEV1 predicted postoperative FEV1, CPpoFEVI customized predicted postoperative FEV1

\section{Discussion}

\section{Is the Accuracy of the ppoFEV1 Dependent on Patients' Characteristics?}

The ppoFEV1 is calculated independently of patient' characteristics $[2,9]$. However, factors that influence the accuracy of the ppoFEV 1 are being identified. Yokoba et al. found that COPD is an independent factor for an inaccurate ppoFEV1. The authors suggest separating the calculation of patients with and without COPD [13].

Wang et al. demonstrated that COPD decreased the accuracy level of the ppoFEV1 independently [14]. COPD was not an independent factor for an inaccurate or accurate ppoFEV1 in our cohort. In Yokoba's cohort, 28 patients (49.2\%) were diagnosed with COPD. In our cohort only $31(35.6 \%)$ were diagnosed with COPD. Emphysema and COPD are substantially underdiagnosed and undertreated in patients under suspicion of lung cancer [15]. Therefore, a higher number of unreported cases can be assumed, especially when we consider the distribution pattern of smoking habits in our cohort. We demonstrated that preoperative smoking habits had a considerable influence on the accuracy levels of the ppoFEV1 in our cohort. Smoking habits in turn directly correlate with the development of COPD [16]. COPD stage could therefore have an impact on ppoFEV1, as stages I and II have a reduced impact on lung function, but patients in stages III and IV show markedly pathological preoperative lung function $[6,7,10]$.

We modified the ppoFEV1 for patient smoking habits specifically active smoking status. We further found younger age to be an independent variable for a more inaccurate 
ppoFEV1 in our cohort. We showed that the ppoFEV1 of patients younger than 55 tended to overestimate compared to the actual postFEV1. This tendency for overestimating the ppoFEV1 decreases in older patients (Fig. 1). To our knowledge this is the first report of this particular inaccuracy. Lung cancer occurs mainly in older people. Most people diagnosed with lung cancer are 65 or older $[16,17]$. Consequently, the ppoFEV1 was primarily developed for this age category, so we adjusted the calculation for ppoFEV1 accordingly for younger patients. It could be speculated that younger patients undergo surgery despite decreased pulmonary reserve as they are often otherwise in good health and surgery is their best chance of survival $[1,18]$. Elderly patients on the other hand are evaluated more carefully to estimate whether surgery is justifiable in their health condition $[19,20]$.

\section{Is the Accuracy of ppoFEV1 Dependent on the Extent of the Resection?}

The ppoFEV1 is calculated based on the number of functional lung segments resected in relation to the total number of functional segments overall $[2,9,12]$. We found that the accuracy of the ppoFEV 1 depended on the lobes being resected. The ppoFEV1 was more accurate if smaller lobes such as the right upper lobe were resected. The middle lobe was an exception, although only 6 patients in our cohort underwent middle lobe resection. Brunelli et al. and Varela et al. also noted this dependence [9,21]. The resection of larger lobes such as the lower left lobe resulted in a significantly inaccurate ppoFEV1 [22]. Similar results were published by Yabucchi et al. and Yokoba et al. [22, 23].

The ppoFEV 1 for pneumectomy was significantly inaccurate overall in our cohort and showed significant variance (Fig. 2). Brunelli et al. reported similar results regarding extended lung resection, suggesting that measurements of ppoFEV1 for pneumectomies need to be reconsidered [13, $14,22]$. Brunelli et al. showed similar results for extended lung resection, even stating, that measurements of ppoFEV1 for risk stratification for pneumectomies need to be reconsidered $[9,13]$. Therefore, we excluded pneumectomy patients for our customized FEV1 (Fig. 2). If pneumectomy is the planned procedure, accurate measurements of the ppoFEV1 are consequently challenging.

\section{Is the Calculation of the ppoFEV1 Prior to Lobectomy Still Necessary?}

According to the guidelines performing lobectomies in patients with a FEV $1<1.51$ and $<50 \%$ DLCO and pneumectomies with a FEV $1<21$ and DLCO $<60 \%$ increases the respiratory morbidity rates substantially $[2,6-8]$. Consequently, one could argue that the calculation of ppoFEV1 is not necessary. Many patients are at the lower limit of these values and especially in these borderline patients, the calculation is even more critical [2,9], because otherwise these patients could be deprived of curative surgery. Ferguson et al. demonstrated in 854 patients that the postFEV1 and ppoFEV 1 are strongly associated with long-term survival after pulmonary resection, considerably more so than the preFEV1 $[6,10]$. Taking this into account, the calculation of the ppoFEV1 remains particularly important and is therefore still a part of the guidelines [23, 24]. Perhaps our modifications to the ppoFEV1 calculation can help render the evaluation of pulmonary operability more accurate in the future.

\section{Conclusion}

The present study demonstrates that heavy smoking and younger age are independent factors for inaccurate ppoFEV1 calculations. Further, we show that the calculation of the ppoFEV1 is not entirely feasible for younger patients, heavy smokers, or patients undergoing pneumectomy. Therefore, we customized ppoFEV1 calculation taking these measures into account. We excluded patients undergoing pneumectomies, added a lung segment into the calculation for patients $<60$ years at the time of surgery and subtracted a lung segment from the calculation for actively smoking patients $>30$ packyears at the time of surgery. We were able to provide evidence that these alterations enhance the ppoFEV1. However, if patients require pneumectomy or are in a marginal pulmonary constitution, more complex techniques to determine the ppoFEV1 should be utilized.

Supplementary Information The online version contains supplementary material available at https://doi.org/10.1007/s00408-021-00464-4.

Funding Open Access funding enabled and organized by Projekt DEAL. This work was not supported by any external funding.

\section{Declarations}

Conflict of interest All authors declare that they have no conflict of interest.

Open Access This article is licensed under a Creative Commons Attribution 4.0 International License, which permits use, sharing, adaptation, distribution and reproduction in any medium or format, as long as you give appropriate credit to the original author(s) and the source, provide a link to the Creative Commons licence, and indicate if changes were made. The images or other third party material in this article are included in the article's Creative Commons licence, unless indicated otherwise in a credit line to the material. If material is not included in the article's Creative Commons licence and your intended use is not permitted by statutory regulation or exceeds the permitted use, you will need to obtain permission directly from the copyright holder. To view a copy of this licence, visit http://creativecommons.org/licenses/by/4.0/. 


\section{References}

1. Postmus PE, Kerr KM, Oudkerk M, Senan S, Waller DA, Vansteenkiste J et al (2017) Early and locally advanced non-small-cell lung cancer (NSCLC): ESMO Clinical Practice Guidelines for diagnosis, treatment and follow-up. Ann Oncol 28:1-21

2. Brunelli A, Kim AW, Berger KI, Addrizzo-Harris DJ (2013) Physiologic evaluation of the patient with lung cancer being considered for resectional surgery: diagnosis and management of lung cancer, 3rd ed: American College of Chest Physicians evidence-based clinical practice guidelines. Chest 143:e166S-e190S

3. Colice GL, Shafazand S, Griffin JP, Keenan R, Bolliger CT (2007) Physiologic evaluation of the patient with lung cancer being considered for resectional surgery: ACCP evidenced-based clinical practice guidelines (2nd edition). Chest 132:161s-177s

4. Ukena A (2018) S3-Leitlinie prävention, diagnostik, therapie und nachsorge, des Lungenkarzinoms. Leitlinienprogr Onkol (Deutsche Krebsgesellschaft, Deutsche Krebshilfe, AWMF) 1:417

5. Planchard D, Popat S, Kerr K, Novello S, Smit EF, Faivre-Finn C et al (2018) Metastatic non-small cell lung cancer: ESMO Clinical Practice Guidelines for diagnosis, treatment and follow-up. Ann Oncol 29:192-237

6. Ferguson MK, Gaissert HA, Grab JD, Sheng S (2009) Pulmonary complications after lung resection in the absence of chronic obstructive pulmonary disease: the predictive role of diffusing capacity. J Thorac Cardiovasc Surg 138:1297-1302

7. Ferguson MK, Vigneswaran WT (2008) Diffusing capacity predicts morbidity after lung resection in patients without obstructive lung disease. Ann Thorac Surg 85:1158-1164

8. Licker MJ, Widikker I, Robert J, Frey JG, Spiliopoulos A, Ellenberger $\mathrm{C}$ et al (2006) Operative mortality and respiratory complications after lung resection for cancer: impact of chronic obstructive pulmonary disease and time trends. Ann Thorac Surg 81:1830-1837

9. Brunelli A, Refai M, Salati M, Xiumé F, Sabbatini A (2007) Predicted versus observed FEV1 and DLCO after major lung resection: a prospective evaluation at different postoperative periods. Ann Thorac Surg 83:1134-1139

10. Ferguson MK, Watson S, Johnson E, Vigneswaran WT (2014) Predicted postoperative lung function is associated with all-cause long-term mortality after major lung resection for cancer. Eur J Cardiothorac Surg 45:660-664

11. Fourdrain A, De Dominicis F, Lafitte S, Iquille J, Prevot F, Lorne E et al (2017) Quantitative computed tomography to predict postoperative FEV1 after lung cancer surgery. $\mathrm{J}$ Thorac Dis 9:2413-2418

12. Bolliger CT, Gückel C, Engel H, Stöhr S, Wyser CP, Schoetzau A et al (2002) Prediction of functional reserves after lung resection: comparison between quantitative computed tomography, scintigraphy, and anatomy. Respir Int Rev Thorac Dis 69:482-489

13. Yokoba M, Ichikawa T, Harada S, Shiomi K, Mikubo M, Ono M et al (2020) Comparison between quantitative computed tomography, scintigraphy, and anatomical methods for prediction of postoperative FEV(1) and DLCO: effects of chronic obstructive pulmonary disease status and resected lobes. J Thorac Dis 12:5269-5280

14. Wang T, Tagayun A, Bogardus A, Qian D, Tiep B, Horak D et al (2007) How accurately can we predict forced expiratory volume in one second after major pulmonary resection? Am Surg 73:1047-1051

15. Lindberg A, Jonsson AC, Rönmark E, Lundgren R, Larsson LG, Lundbäck B (2005) Prevalence of chronic obstructive pulmonary disease according to BTS, ERS, GOLD and ATS criteria in relation to doctor's diagnosis, symptoms, age, gender, and smoking habits. Respir Int Rev Thorac Dis 72:471-479

16. Muller DC, Johansson M, Brennan P (2017) Lung cancer risk prediction model incorporating lung function: development and validation in the UK Biobank Prospective Cohort Study. J Clin Oncol 35:861-869

17. de Koning HJ, van der Aalst CM, de Jong PA, Scholten ET, Nackaerts K, Heuvelmans MA et al (2020) Reduced lung-cancer mortality with volume $\mathrm{CT}$ screening in a randomized trial. N Engl J Med 382:503-513

18. Eberhardt WE, De Ruysscher D, Weder W, Le Pechoux C, De Leyn P, Hoffmann H et al (2015) 2nd ESMO Consensus Conference in Lung Cancer: locally advanced stage III non-small-cell lung cancer. Ann Oncol 26:1573-1588

19. Chambers A, Routledge T, Pilling J, Scarci M (2010) In elderly patients with lung cancer is resection justified in terms of morbidity, mortality and residual quality of life? Interact Cardiovasc Thorac Surg 10:1015-1021

20. Pan X, Tantai J, Lin L, Cao K, Zhao H (2014) Comparison of short and long-term results between sleeve resection and pneumonectomy in lung cancer patients over 70 years old: 10 years experience from a single institution in China. Thorac Cancer 5:494-499

21. Varela G, Jiménez MF, Novoa N, Macrí P (2003) Discordance between predicted postoperative forced expiratory volumes in one second (ppoFEV1) calculated before and after resection of bronchogenic carcinoma. Interact Cardiovasc Thorac Surg 2:138-142

22. Yokoba M, Ichikawa T, Harada S, Naito M, Sato Y, Katagiri M (2018) Postoperative pulmonary function changes according to the resected lobe: a 1-year follow-up study of lobectomized patients. J Thorac Dis 10:6891-6902

23. Yabuuchi H, Kawanami S, Kamitani T, Yonezawa M, Yamasaki Y, Yamanouchi T et al (2016) Prediction of post-operative pulmonary function after lobectomy for primary lung cancer: a comparison among counting method, effective lobar volume, and lobar collapsibility using inspiratory/expiratory CT. Eur J Radiol 85:1956-1962

24. Morice RC, Jimenez CA, Eapen GA, Mehran RJ, Keus L, Ost D (2010) Using quantitative breath sound measurements to predict lung function following resection. J Cardiothorac Surg 5:81

Publisher's Note Springer Nature remains neutral with regard to jurisdictional claims in published maps and institutional affiliations. 